\title{
NOTES
}

\section{Recovery of Constituent Monomers from Polyethylene Terephthalate with Supercritical Methanol}

\author{
Takeshi Sako, Idzumi Okajima, Tsutomu Sugeta, Katsuto Otake, Satoshi Yoda, \\ Yoshihiro TAKEBAYASHI, and Chiyoshi Kamizawa \\ National Institute of Materials and Chemical Research, Higashi 1-1, Tsukuba, Ibaraki, 305-8565, Japan
}

(Received July 16, 1999)

KEY WORDS Chemical Recycling / Supercritical Methanol / Polyethylene Terephthalate /

The amount of the recovery of polyethylene terephthalate (PET) bottles is increasing year by year due to the enforce of the law for promotion of sorted collection and recycling of containers and packaging from $1997 .{ }^{1,2}$ At present, the collected PET bottles undergo the material recycling to the textile goods such as the dress shirts, carpets and others. It is expected that the collected PET will increase to 89000 tons in 2001 that will be more than 4 times the amount in 1997. However, if we perform only the material recycling, it will be difficult to consume the recycling goods completely. Therefore the research and development of the chemical recycling of the PET to its constituent monomers is necessary for the effective PET reuse.

A number of depolymerization techniques of the PET with liquid solvents have been reported until now. The solvents used are an alcohol such as methanol ${ }^{3}$ or ethylene glycol, ${ }^{4}$ and water with an acid $^{5}$ or alkali ${ }^{5}$ catalyst. Methanolysis by liquid methanol is carried out at $180^{\circ} \mathrm{C}$ and $2.5 \mathrm{MPa}$ with a catalyst such as zinc acetate and the monomers of dimethyl terephthalate (DMT) and ethylene glycol (EG) are recovered with high yield. Glycolysis by liquid EG is also performed with zinc acetate catalyst at $190-200^{\circ} \mathrm{C}$ and $3-4 \mathrm{MPa}$. In this method, the products are low-molecular-weight oligomers. Hydrolysis with $\mathrm{H}_{2} \mathrm{SO}_{4}$ can recover both terephthalic acid (TPA) and EG monomers at $150^{\circ} \mathrm{C}$ and $0.48 \mathrm{MPa}$. For the hydrolysis with $\mathrm{NaOH}$ at $250^{\circ} \mathrm{C}$ and $5 \mathrm{MPa}$, the recovery of the TPA monomer is about $100 \%$ but that of the EG is only $50 \%$, because the EG is oxidized to oxalic acid. These depolymerization methods using liquid solvents require the long reaction time of more than $5 \mathrm{~h}$, in spite of using the catalyst.

Recently much attention is given to the decomposition methods using supercritical fluids. Adschiri et al. reported that the PET was decomposed completely to the monomers by the supercritical water $\left(T_{\mathrm{c}}=374.1^{\circ} \mathrm{C}, P_{\mathrm{c}}=\right.$ $22.12 \mathrm{MPa})$ at $400^{\circ} \mathrm{C}, 40 \mathrm{MPa}$ and $5 \mathrm{~min}$ of the reaction time. ${ }^{6}$ Under this condition, the TPA monomer was recovered almost completely, but the recovery of the EG monomer was less than $30 \%$. The EG monomer was decomposed to small molecules in the presence of water and TPA working as an acid catalyst. The authors proposed that the PET was decomposed completely by the supercritical methanol (SC-methanol, $T_{\mathrm{c}}=239.4^{\circ} \mathrm{C}, P_{\mathrm{c}}=$ $8.09 \mathrm{MPa})$ at $300^{\circ} \mathrm{C}, 8 \mathrm{MPa}$ and $30 \mathrm{~min}$ of the reaction time $^{7,8}$ The products were the DMT monomer, EG monomer and low-molecular-weight oligomers which could be treated as the same as the monomers. The recovery of both monomers was about $100 \%$. In addition, this method did not need any catalyst to promote the reaction and the depolymerization completed at a short reaction time.

In this work, we investigated the effect of the temperature, pressure and reaction time on the monomer recovery and determined the proper conditions for the depolymerization of the PET to the DMT and EG monomers with the SC-methanol.

\section{EXPERIMENTAL}

Figure 1 shows the experimental apparatus used for the PET decomposition. The reactor was made of SUS 316 and its inner volume was about $20 \mathrm{~cm}^{3}$. The maximum working temperature and pressure of the reactor were $400^{\circ} \mathrm{C}$ and $40 \mathrm{MPa}$, respectively.

The experimental procedure was as follows. The PET of $0.5 \mathrm{~g}$ and methanol were loaded into the reactor. The amount of methanol was adjusted to get a desired reaction pressure at a reaction temperature. Then the air in the reactor was replaced with argon gas. The reactor was closed and put into the sand bath which was already heated to the reaction temperature. This moment was the starting time of the reaction. It took about $5 \mathrm{~min}$ for the reactor to reach the setting reaction temperature. The reaction temperature was assumed to be equal to the temperature of the sand bath. The reaction pressure was monitored using a digital pressure gauge during the experiment. After a given reaction time, the reactor was taken out of the sand bath and cooled quickly in water to stop the reaction as soon as possible. Then the gaseous product was collected into a sampling bag, and the liquid and solid products were collected with methanol and analyzed by GC and GC/MS.

The PET was decomposed to the DMT and EG monomers via oligomers by the SC-methanol. Figure 2 shows the pathway of the methanolysis of the PET using the SC-methanol.

Figure 3 shows the analytical procedure of the products of the PET decomposition. The product contained the monomers of the DMT and EG, oligomers linking some units of the monomers, unreacted PET and methanol. In this work the oligomer was defined as the product which was hydrolyzed with $\mathrm{NaOH}$ aqueous solution to the TPA and EG. In the first step, the product was separated into a solid (called solid 1) and a liquid (liquid 1) 


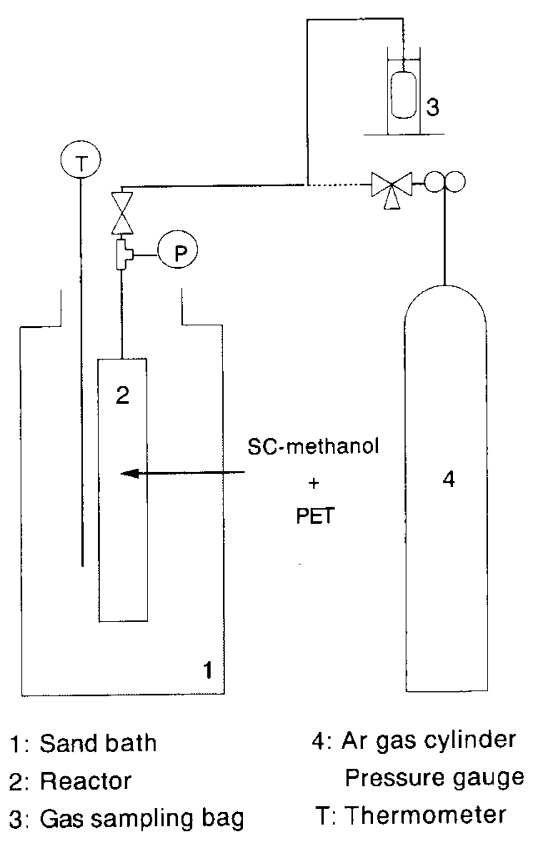

Figure 1. Experimental apparatus used for decomposition of PET.

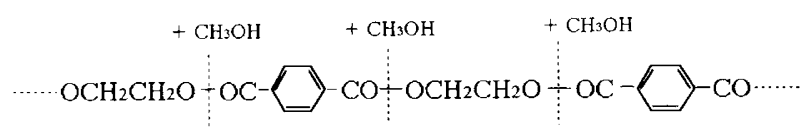

PET

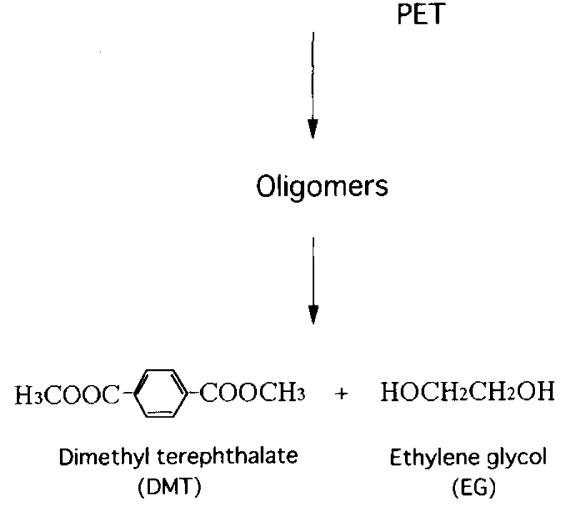

Figure 2. Decomposition of PET with SC-methanol.

phases using the filtration. The solid 1 contained a part of the oligomer, which did not dissolve in the liquid 1 owing to the solubility limitation, and the unreacted PET. The liquid 1 contained the DMT and EG monomers and some part of the oligomer.

Each component in the solid 1 was analyzed as follows. After the removal of methanol by heating at $323 \mathrm{~K}$ in an air bath, the oligomer was decomposed with $1 \mathrm{~N} \mathrm{NaOH}$ aqueous solution to disodium terephthalate (NaTPA) and EG. The solution was filtered to a solid 2 and a liquid 2. The solid 2 was the unreacted PET and was weighed using a balance after drying at $323 \mathrm{~K}$. The liquid 2 contained NaTPA and EG obtained from the oligomer decomposition. The NaTPA was precipitated from the liquid 2 by adding $\mathrm{HCl}$ aqueous solution and separated with the filtration. The solid was the TPA and called a solid 4 . The solid 4 was weighed after drying. Each component in the liquid 1 was analyzed in the same manner as that in the solid 1 . There is a point in which we have

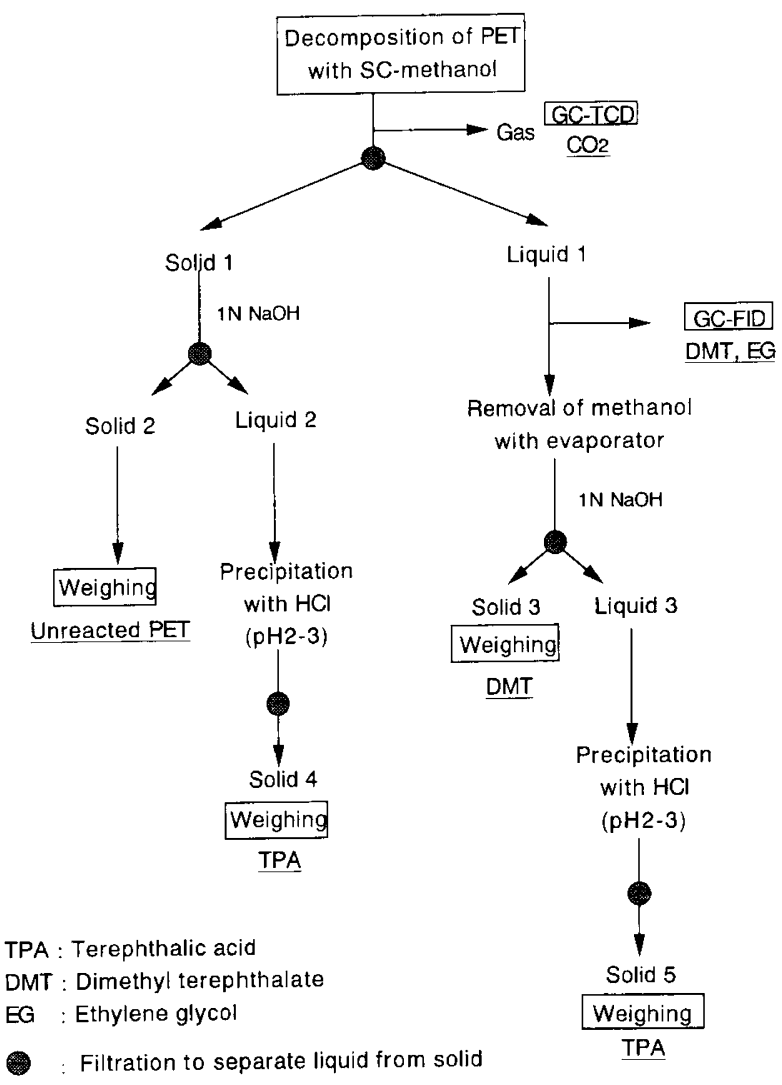

Figure 3. Analytical procedure for PET decomposition.

to be careful for the determination of the amount of the oligomer in the liquid 1 . Because a part of the DMT monomer dissolved into $\mathrm{NaOH}$ solution during the decomposition of the oligomer, a solid 5 contained the TPA from both the oligomer and DMT monomer. As the result, a solid 3 was the DMT monomer which did not decompose with $\mathrm{NaOH}$ solution. Therefore the real amount of the TPA from the oligomer was determined by that (the amount of the TPA in the solid 5)-(the amount of the TPA from the DMT monomer), where the latter amount was calculated by the subtraction of the amount of the DMT monomer in the solid 3 from that in the liquid 1.

Finally the unreacted PET was recovered as the solid 2, the DMT and EG monomers as the liquid 1, the DMT component in the oligomer as the solids 4 and a part of the solid 5. The EG component in the oligomer dissolving in the liquids 2 and 3 was not analyzed by the GC because the alkaline solution or the salt obtained by neutralizing the alkaline solution gave the serious damage to the GC column. This amount was calculated by a simple method mentioned after.

The accuracies of the measurement of the reaction temperature and pressure were $1 \mathrm{~K}$ and $0.2 \mathrm{MPa}$, respectively. The gas chromatograph was calibrated by injecting various amounts of pure components and analyzed in the range where the peak area was linear with the sample amounts. The analytical accuracy of the GC was $\pm 1.0 \%$.

The methanol was supplied by Wako Pure Chemical Industries, Ltd. and its purity was higher than $99.8 \%$. The PET was provided by Aldrich Chemical Co., and its 


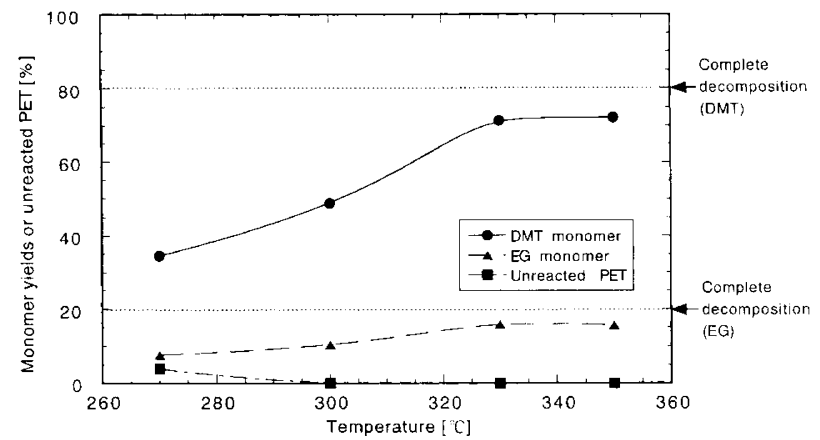

Figure 4. Temperature dependence of yields of DMT and EG monomers (pressure $=9.8 \mathrm{MPa}$, reaction time $=30 \mathrm{~min}$, mole ratio of $\mathrm{MeOH} / \mathrm{PET}=43)$.

IV was 0.57 . The DMT and EG used for the GC calibration were provided by Wako Pure Chemical Industries, Ltd.

\section{RESULTS AND DISCUSSION}

In this work, the yield of each component was calculated based on the number of carbon atoms in its structural formula as follows ;

Yield of DMT monomer $(\%)=$

$\frac{\text { Moles of produced DMT monomer } \times 8}{\left[\frac{\text { Grams of charged PET }}{\text { Formula weight of a repeating segment of PET }}\right] \times 10} \times 100$

Yield of EG monomer $(\%)=$

$\left[\frac{\text { Moles of produced EG monomer } \times 2}{\text { Frams of charged PET }}\right] \times 10$

Rate of unreacted PET $(\%)=\frac{\text { Grams of unreacted PET }}{\text { Grams of charged PET }} \times 100$

where the formula weight of a repeating segment of the PET was 192.2. When the PET was decomposed to the monomers completely, the maximum yields of the DMT and EG monomers were $80 \%$ and $20 \%$. The yield of the DMT component in the oligomer was calculated from the above equation for the yield of the DMT monomer by replacing the moles of produced DMT monomer by those of the DMT component in the oligomer. On the other hand, the yield of the EG component in the oligomer was obtained by the subtraction of the yield of the EG monomer from the EG maximum yield (20\%).

Figure 4 shows the temperature dependence of the yields of both monomers at $9.8 \mathrm{MPa}$, the reaction time of $30 \mathrm{~min}$ and the mole ratio of methanol/PET of 43 . About $3 \%$ of the unreacted PET remained at $270^{\circ} \mathrm{C}$. The PET was decomposed completely at $300^{\circ} \mathrm{C}$ and the yields of the DMT and EG monomers were $49 \%$ and $10 \%$, respectively. The yields of the DMT and EG monomers increased to about $70 \%$ and $16 \%$ as the reaction temperature increased to $330^{\circ} \mathrm{C}$. This result showed that $92 \%$ of the DMT monomer and $80 \%$ of the EG monomer were recovered on the basis of the maximum yield. Moreover the gaseous components were hardly produced.

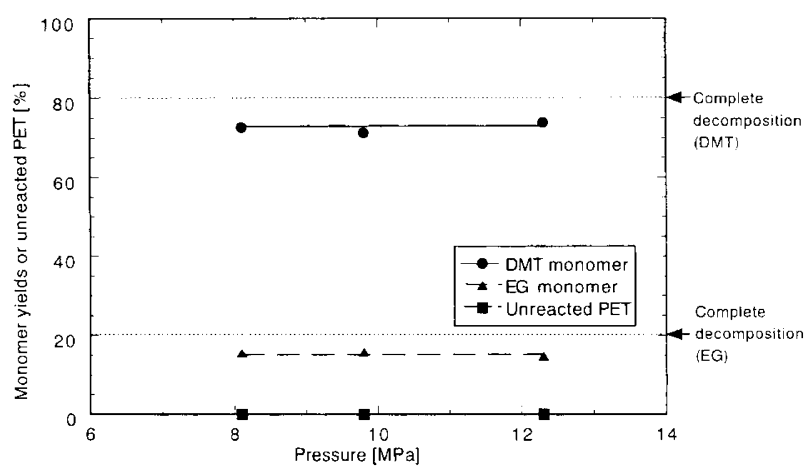

Figure 5. Pressure dependence of yields of DMT and EG monomers $\left(\right.$ temp $=330^{\circ} \mathrm{C}$, reaction time $=30 \mathrm{~min}$, mole ratio of $\mathrm{MeOH} /$ $\mathrm{PET}=43$ ).

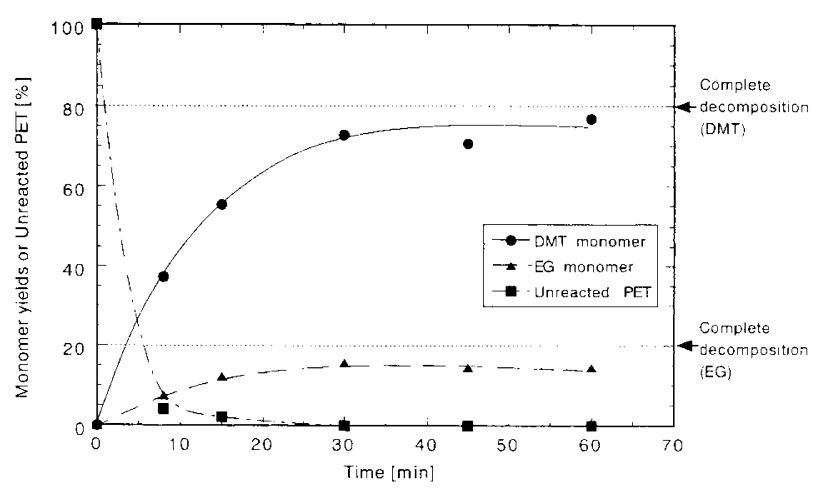

Figure 6. Reaction time dependence of yields of DMT and EG monomers $\left(\right.$ temp $=330^{\circ} \mathrm{C}$, pressure $=8.1 \mathrm{MPa}$, mole ratio of $\mathrm{MeOH} /$ $\mathrm{PET}=43$ ).

When the reaction temperature increased to $350^{\circ} \mathrm{C}$, the yield of each monomer changed little, but the amount of the gaseous product increased slightly and the main component was $\mathrm{CO}_{2}$. Judging from the experimental results, the best temperature condition for the depolymerization of the PET was $330^{\circ} \mathrm{C}$ because the yield of each monomer was high and the gas did not produce.

Figure 5 shows the pressure dependence of both yields of both monomers. The reaction pressure was changed from 8.1 to $12.3 \mathrm{MPa}$, but the yields of each monomer were almost constant with pressure. As the result, the best pressure at $330^{\circ} \mathrm{C}$ was $8.1 \mathrm{MPa}$, which was the lowest pressure condition in this experiment.

Figure 6 shows the dependence of the yields of both monomers on the reaction time. The unreacted PET remained in about $2 \%$ at $15 \mathrm{~min}$ of the reaction time. Then the PET was decomposed completely, as the reaction time extended to $30 \mathrm{~min}$. The yield of the DMT monomer at $30 \mathrm{~min}$ was $73 \%$, which corresponded to $94 \%$ of the maximum yield, and that of the EG monomer was $16 \%$, which corresponded to $80 \%$ of the maximum yield. While $7 \%$ of the rest of the DMT component was the oligomer, $4 \%$ of the rest of the EG component was the mixture of the oligomer and by-products. The GC/MS analysis showed that the oligomer was low-molecular-weight compounds such as those composed of $1: 1$ monomer and the main by-products of the EG were diethylene glycol and 2-methoxyethanol. When the reaction time increased further, the yield of each product hardly 
changed but the gaseous product increased. Because the chemical equilibrium was attained relatively rapidly between the monomers and oligomers, the ratio of the monomers did not change much with the reaction time.

\section{CONCLUSION}

SC-methanol depolymerized the PET to the DMT and EG monomers with $94 \%$ and $80 \%$ recovery of the maximum yield. In addition, the secondary decomposition or the side reactions of the monomers could be minimized using SC-methanol.

\section{REFERENCES AND NOTES}

1. N. Kusakawa, Plastic Age, 44, 156 (1998)

2. H. Miwa, Kogyozairyo, 46, 23 (1998).

3. H. Grunschke, W. Hammerschick, and B. Naucheim, US Patent 3403115 (1968)

4. S. Baliga, and W. T. Wong, J. Polym. Sci., Part A : Polym. Chem., 27,2071 (1989).

5. T. Yoshioka, and A. Okuwaki, Ryusan to kogyo, 47, 21(1994).

6. M. Adschiri, O. Sato, K. Machida, I. Saito, and K. Arai, Kagakukogaku Ronbunshu, 23, 505 (1997).

7. T. Sako, T. Sugeta, K. Otake, N. Nakazawa, M. Sato, K. Namiki, and M. Tsugumi, J. Chem. Eng. Japan, 30, 342 (1997).

8. T. Sako, T. Sugeta, K. Otake, Y. Takebayashi, C. Kamizawa, M. Tsugumi, and M. Hongo, Kobunshi Ronbunshu, 55, 11 (1998). 